\title{
The fate of a southwest Pacific bloom: gauging the impact of submesoscale vs. mesoscale circulation on biological gradients in the subtropics
}

\author{
Alain de Verneil, Louise Rousselet, Andrea M. Doglioli, Anne A. Petrenko, and Thierry Moutin \\ Aix Marseille University, Université de Toulon, CNRS, IRD, Mediterranean Institute of Oceanography MIO, UM 110, 13288, \\ Marseille, CEDEX 09, France \\ Correspondence to: Alain de Verneil (alain.de-verneil@mio.osupytheas.fr)
}

Received: 10 March 2017 - Discussion started: 21 March 2017

Revised: 28 June 2017 - Accepted: 30 June 2017 - Published: 24 July 2017

\begin{abstract}
The temporal evolution of a surface chlorophyll $a$ bloom sampled in the western tropical South Pacific during the 2015 Oligotrophy to UlTra-oligotrophy PACific Experiment (OUTPACE) cruise is examined. This region is usually characterized by largely oligotrophic conditions, i.e. low concentrations of inorganic nutrients at the surface and deep chlorophyll a maxima. Therefore, the presence of a surface bloom represents a significant perturbation from the mean ecological state. Combining in situ and remote sensing datasets, we characterize both the bloom's biogeochemical properties and the physical circulation responsible for structuring it. Biogeochemical observations of the bloom document the bloom itself, a subsequent decrease of surface chlorophyll $a$, significantly reduced surface phosphate concentrations relative to subtropical gyre water farther east, and a physical decoupling of chlorophyll $a$ from a deep nitracline. All these characteristics are consistent with nitrogen fixation occurring within the bloom. The physical data suggest surface mesoscale circulation is the primary mechanism driving the bloom's advection, whereas balanced motions expected at submesoscales provide little contribution to observed flow. Together, the data provide a narrative where subtropical gyre water can produce significant chlorophyll $a$ concentrations at the surface that is stirred, deformed, and transported great distances by the mesoscale circulation. In this case, for the time period considered, the transport is in an easterly direction, contrary to both the large-scale and mean mesoscale flow. As a result, future studies concerning surface production in the region need to take into account the role complex mesoscale structures play in redistributing subtropical gyre water.
\end{abstract}

\section{Introduction}

Subtropical gyres and their surroundings represent the largest surface biological provinces in areal extent. These regions are characterized by low standing stocks of phytoplankton biomass with deep chlorophyll $a(\operatorname{chl} a)$ maxima (DCM) and low surface nutrient concentrations. The South Pacific gyre (SPG) is the world's largest gyre and the most remote from large landmasses. Due to its remoteness, in situ data are generally lacking from the region; however, previous studies corroborate the oligotrophic status of this region (Claustre et al., 2008). Among oligotrophic areas, the SPG appears to be a low chlorophyll area with low $\mathrm{N}_{2}$ fixation rates and high residual phosphate, suggesting biological carbon pump inefficiency (Moutin et al., 2008). Flowing from the east, the waters from the SPG reach the western tropical South Pacific (WTSP), which has been recently shown to be the world hotspot for $\mathrm{N}_{2}$ fixation (Bonnet et al., 2017), a process considered to be the largest external nitrogen source to the ocean (Sohm et al., 2011). Therefore, the physical processes that structure the gyre and nearby areas must be investigated.

Marine biological communities at any moment reflect a time integration of the many complex interactions that occur both within the community and with the physical environment (Longhurst, 2010). An important structuring mechanisms of biological communities is the presence of gradients. In the terrestrial and conservation biology literature, these impacts are dubbed "edge effects" (Harris, 1988) and have important implications for predation processes and species survival. Horizontal patch edges and biological transitions in the ocean are liable to being advected by the surface circu- 
lation. Thus, it is necessary to identify the character of the flows that shape these horizontal gradients.

In recent decades, accumulating satellite data and highresolution modeling studies highlight how complex the surface ocean circulation really is beyond the mean flow, with several consequences. First, most kinetic energy in the surface ocean is found at the mesoscale, in eddies and frontal structures evolving over weeks and months (Stammer, 1997; Ferrari and Wunsch, 2009), so in a given field campaign these features can be the most important. Second, nonlinear eddy structures (i.e. "rings") can be long-lived and transport water long distances (Chelton et al., 2007; Rousselet et al., 2016). These rings host their own biological dynamics, as well, which impact the biological pump (McGillicuddy et al., 2007; Nencioli et al., 2008; Moutin et al., 2012). Third, mesoscale motions can provide energy to the submesoscale through frontogenesis and filamentation, producing motions with much shorter timescales and relatively vigorous vertical circulation (Mahadevan and Tandon, 2006; Thomas et al., 2008; Mahadevan, 2016). Taken all together, these characteristics of surface ocean flow elucidate the importance of the mesoscale and submesoscale (hereafter (sub)mesoscale when referred together) circulation in determining the spatial pattern of biological communities, with recent modeling work taking into account the role they play in moving around biological production at a regional scale (Nagai et al., 2015).

The WTSP presents an ideal laboratory in which to assess the impact of (sub)mesoscale circulation upon planktonic communities in the gyre and nearby. In the WTSP, the SPG's northern limb, the South Equatorial Current (SEC), flows west into the Melanesian Archipelago group (MA) (Chaigneau and Pizarro, 2005). Though the SEC is relatively oligotrophic throughout, the depth of the DCM shoals as it moves west past these island groups, indicative of reduced oligotrophy. Sampling of this zonal gradient was the focus of the Oligotrophy to UITra-oligotrophy PACific Experiment (OUTPACE) cruise during austral summer 2015 aboard the RV L'Atalante (Moutin and Bonnet, 2015). The main biogeochemical goals of OUTPACE concerned the study of biological production and its fate in a gradient of trophic conditions, from the ultra-oligotrophic conditions of the SPG to the oligotrophic conditions of the MA (Moutin et al., 2017). During the cruise, however, a strong surface chl $a$ bloom was detected from satellite data and intensively sampled for 5 days during long-duration (LD) station LDB. The presence of this surface bloom, itself a marked departure from the usual oligotrophic DCM pattern, in a region known to host production fueled by $\mathrm{N}_{2}$ fixation at the surface brings into sharp focus the need to quantify and contextualize the relevant (sub)mesoscale circulation, also intensified near the surface, that might influence and structure this bloom.

In this study, we use a combination of in situ and remote sensing data to describe the bloom's distribution and evaluate both its temporal evolution and what role the (sub)mesoscale current field may play in structuring it. We outline the sources of data, their processing, and the analyses required to investigate the bloom in Sect. 2. Subsequently, Sect. 3 summarizes the results from the calculations performed. After a discussion of the results in Sect. 4, we provide conclusions and possible applications of our approach in Sect. 5.

\section{Materials and methods}

\subsection{Cruise sampling plan and context}

In situ data for this study come from the OUTPACE cruise, conducted from 18 February to 3 April 2015 in the WTSP on the French RV L'Atalante. Over a mostly zonal transect beginning west of New Caledonia and ending near Tahiti (Fig. 1), the ship sampled in two main ways: first, the shortduration (SD) stations and, second, the LD stations. For the 15 SD stations, referred to by their number in chronological order, conductivity-temperature-depth (CTD) casts and biogeochemical measurements were taken over a $24 \mathrm{~h}$ period, as described in Moutin et al. (2017, this special issue). During the three LD stations, referred to as stations LDA, LDB, and LDC, a quasi-Lagrangian drift array was deployed with sediment traps. The ship largely followed the trajectory of this array. Multiple CTD casts were performed, spaced every $3 \mathrm{~h}$. The position of each station was chosen using the SPASSO software suite (Doglioli, 2013), which analyzes near-realtime remote sensing data so that an onshore collaborator can provide daily updates regarding the location of possible coherent structures such as eddies (Doglioli et al., 2013). Station LDB was selected because of the large surface chl $a$ signal as seen from satellites (Fig. 1b). The data used specifically in this study were derived from SD12, LDB, and SD13. For these purposes, we defined the general region of interest as $184-192^{\circ} \mathrm{E}$ and $22-16^{\circ} \mathrm{S}$ (Fig. 1b).

In situ sampling for SD12, LDB, and SD13 took place during 11-12, 14-20, and 21 March 2015, respectively. Before the deployment of the drift array during LDB, a survey of the area was conducted by a Moving Vessel Profiler (MVP; Brooke Oceanographic) platform, allowing for highresolution CTD profiles over three separate transects $(\mathrm{T} 1, \mathrm{~T} 2$, and T3 in Fig. 2a). Subsequent to the multi-day drift-array experiments, a final MVP transect was conducted as well (T4).

\subsection{In situ data}

\subsubsection{CTD, bottle data, MLD, and nitracline depth}

The shipboard CTD rosette was deployed four times at SD12, 47 times during LDB, and once for SD13. The rosette layout was the Sea-Bird SBE 9plus CTD rosette, with two CTDs installed on the rosette and a chl $a$ fluorometer (Chelsea Aqua 3). CTD data were calibrated and processed post-cruise using Sea-Bird Electronics software into $1 \mathrm{~m}$ bins. Chl $a$ fluorescence was calibrated to chl $a$ extractions taken from bottle 

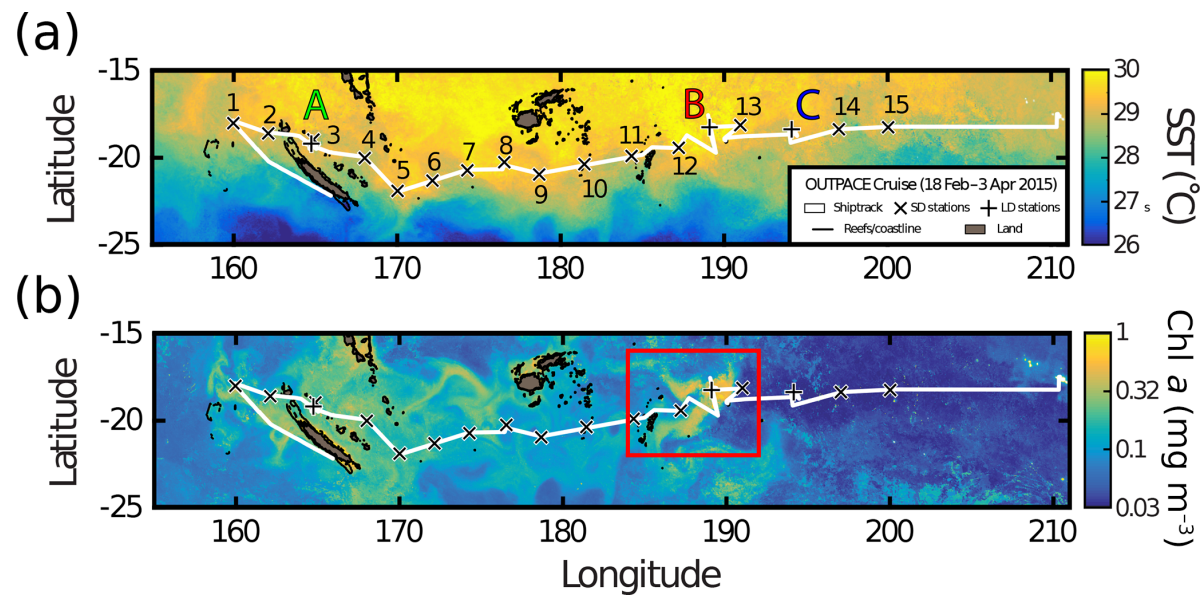

Figure 1. OUTPACE satellite (a) SST and (b) chl $a$. Satellite pixel data over 42 days are used to produce a weighted mean. The weight for each pixel is calculated by normalized inverse distance squared from the pixel to the daily mean ship position. The ship track, derived from SADCP data, is shown in white, while land is shaded gray, with black coastlines and reefs. Short-duration (SD) stations are depicted by black X marks, while long-duration (LD) stations are shown by black + signs. The LD stations are color-coded, using the convention for the OUTPACE cruise. A red rectangle in the chl $a$ panel shows the study area for this paper.

samples throughout the cruise. No corrections were made for the daily oscillations due to non-photochemical quenching.

Subsequent to CTD processing and calibration, each profile's density was reordered to be stable so that small residual overturns were removed. Casts were spaced approximately $3 \mathrm{~h}$ apart, so density and chl $a$ were interpolated to a regular $3 \mathrm{~h}$ interval using cubic polynomials. A horizontal smoothing of density was performed using a locally weighted scatterplot smoothing (LOWESS) filter with a window of four data points, equivalent to $12 \mathrm{~h}$. This time span, designed to remove some internal waves, is about one-third of the inertial period $(\sim 36 \mathrm{~h})$ and does not remove the movements present due to near-inertial oscillations, a dominant signature in the shipboard acoustic doppler current profiler (SADCP) data (Bouruet-Aubertot et al., 2017, this special issue).

Mixed layer depth (MLD) was calculated using a threshold density deviation of $0.03 \mathrm{~kg} \mathrm{~m}^{-3}$ from the value at a reference depth. The CTD profiles post-calibration did not always contain surface values, so a $10 \mathrm{~m}$ reference depth was used, similar to (de Boyer Montégut et al., 2004).

Measurements of dissolved nitrate and phosphate concentrations were conducted for two casts at SD12, seven casts at LDB, and the single cast of SD13. The nitrate and phosphate concentrations were measured using continuous flow analysis (SEAL AutoAnalyzer 3) following the procedures in (Aminot and Kérouel, 2007). Quantification limits for all nutrients are $0.05 \mu \mathrm{mol} \mathrm{kg}^{-1}$. LDB nitracline depth was calculated for the last CTD associated with the drift-array recovery. The nitracline depth $\left(D_{\mathrm{NO}_{3}}\right)$ and its slope $\left(S_{\mathrm{NO}_{3}}\right)$ were calculated performing a linear fit with the first three measurements above the threshold of $0.05 \mu \mathrm{mol} \mathrm{kg}{ }^{-1}$, resulting in $D_{\mathrm{NO}_{3}}=121 \mathrm{~m}$ and $S_{\mathrm{NO}_{3}}=48 \mu \mathrm{mol} \mathrm{m}{ }^{-4}$. The den- sity anomaly at $D_{\mathrm{NO}_{3}}$ for this cast, $24.34 \mathrm{~kg} \mathrm{~m}^{-3}$, was subsequently used for the rest of the LDB time series.

\subsubsection{MVP}

The MVP was used during four transects, three (T1-T3) before LDB and one after (T4) (Fig. 2a). Prior to LDB, we have T1, going northwest to southeast; T2, going south to north; and T3, going north to south in the same path as T2. For these three transects, a total of 388 casts spanning $\sim 700 \mathrm{~km}$ distance were obtained, producing an average horizontal resolution of $\sim 2 \mathrm{~km}$. Subsequent to LDB, T4 traveled west to east from LDB's position, resulting in 95 casts over $\sim 170 \mathrm{~km}$ horizontal distance.

The MVP vehicle sampled vertically by freewheeling the synthetic cable attached to the MVP fish, allowing for a nearvertical descent at $\sim 4 \mathrm{~m} \mathrm{~s}^{-1}$. At a prescribed depth (here, $350 \mathrm{dBar}$ ), the brake was applied to the computer-controlled winch and the fish automatically brought back to the surface. Only downcasts were used in this dataset due to the deployment method.

Onboard the fish was a rapid response AML microconductivity sensor, thermistor, and WET Labs WETStar chl $a$ fluorometer. Due to technical difficulties onboard the ship, the conductivity sensor was swapped for a sound velocity sensor. In order to calculate salinity, the roots of the sound speed equation from (Chen and Millero, 1977) were matched with Mackenzie's linear approximation (1981). Sound speed and temperature data were lag-corrected to reduce salinity spiking. The variability in calculated salinity from the sound speed is larger than that calculated with conductivity (Fig. S1 in the Supplement), but due to the greater contribution of temperature to stratification the resulting density 

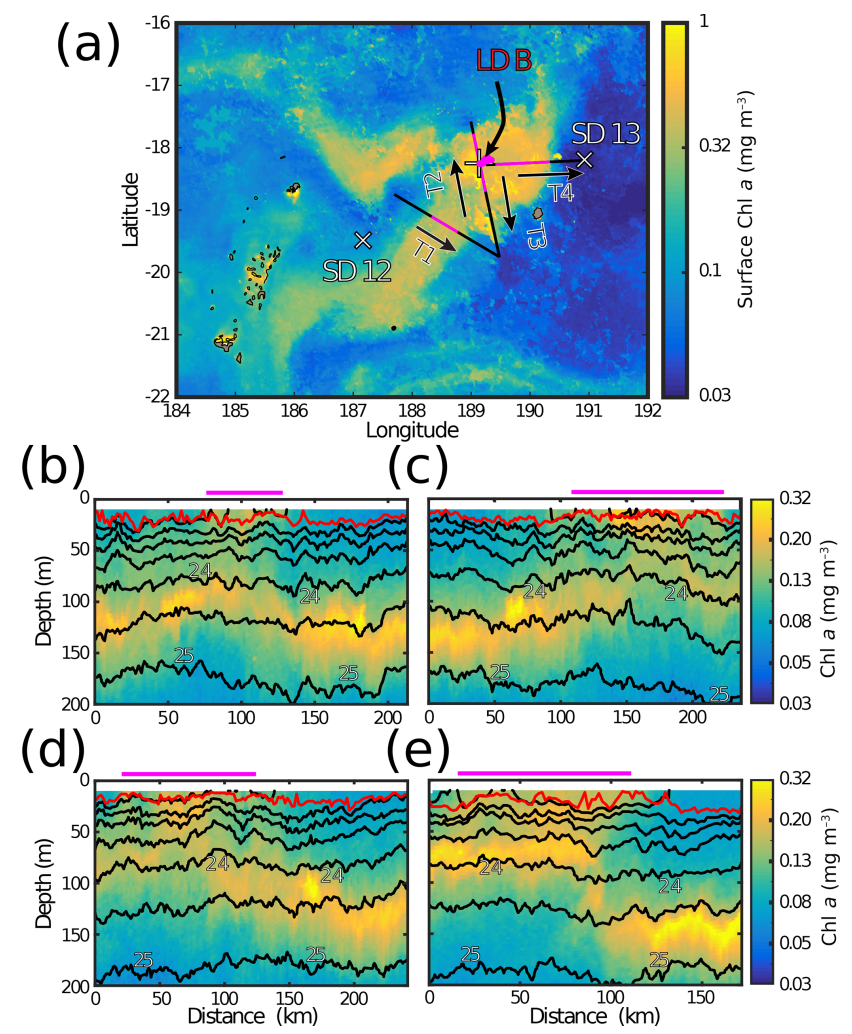

Figure 2. MVP transects near the station B bloom site. (a) The position of each transect with respect to chl $a$ fluorescence transects for (b) Transect 1 (T1), (c) Transect 2 (T2), (d) Transect 3 (T3), and (e) Transect 4 (T4). Transect positions are shown by black lines, with the casts designated inside the bloom by MVP data colored magenta. Stations SD12, LDB, and SD13 are depicted by marks similar to Fig. 1. Locations of LDB CTDs are shown in a cluster around the mark designating LDB. Direction of sampling for the transects are shown by arrows. Islands and reefs are also shown in a similar fashion to Fig. 1. In situ isopycnals are shown in black, ranging from 22 to $25 \mathrm{~kg} \mathrm{~m}^{-3}$ in half-steps. The MLD is shown in red, and the magenta lines above the panels show the casts inside the bloom.

profiles compare well with the CTD (Fig. S2, $\rho=0.998$, $\left.r^{2}=0.996\right)$. A previous study utilizing MVP data found an operational threshold binning of $\sim 1 \mathrm{~m}$ in the vertical ( $\mathrm{Li}$ et al., 2012), which we followed here. Temperature and calculated salinity were calibrated to the station SD13 CTD cast made adjacent to and soon after the last MVP profile of T4. Chl $a$ values were calculated by calibrating to the already calibrated CTD fluorometer values for SD13, as well.

MVP density profiles, as with CTD data, were first reordered to be statically stable. In contrast to the CTD data, horizontal distance, and not time, is the relevant variable. As discussed below (Sect. 2.4), the stratification was such that, even at $2 \mathrm{~km}$ resolution, density structures associated with balanced currents near the surface might be missed, so no additional filtering was applied to density in the MVP dataset despite possible aliasing of internal waves. The $R i_{g}$ num- ber analysis detailed in Sect. 2.4 can be sensitive to these aliased waves and possibly bias the results. While, in general, this processing step should be considered, sensitivity analysis shown in the Supplement (Fig. S3) revealed that the lack of filtering with the current dataset did not affect the resulting conclusions.

In order to determine when the ship was in the surface bloom, a threshold value was chosen. Inspection of chl $a$ in the upper $20 \mathrm{~m}$ revealed a bimodal distribution. As a result, the value of $0.13 \mu \mathrm{g} \mathrm{L}^{-1}$, well above the lower mode and representing the $66 \%$ value of the cumulative distribution function, was selected. Therefore, by our definition the MVP entered the surface bloom when the average value of chl $a$ in the top $20 \mathrm{~m}$ surpassed this value. Additionally, the MLD for the MVP transects were calculated from the same method as the CTD casts, by finding the depth where density surpasses $0.03 \mathrm{~kg} \mathrm{~m}^{-3}$ above the value at $10 \mathrm{~m}$.

\subsubsection{SADCP}

The RV L'Atalante has two SADCPs, RDI Ocean Surveyors with frequencies of 75 and $150 \mathrm{kHz}$. In order to maximize vertical resolution, we use the $150 \mathrm{kHz}$ data in this study. Single ping data were collected into $2 \mathrm{~min}$ intervals, with vertical bins spanning $8 \mathrm{~m}$. Binned data were processed with the Cascade (Le Bot et al., 2011) software package provided by IFREMER. The Cascade procedure corrects for, among other quantities, the horizontal SADCP-navigation misalignment as well as misalignment of the horizontal plane due to ship roll. In addition, within Cascade the barotropic tidal component was removed using the TOPEX/POSEIDON inverse model (Egbert et al., 1994).

\subsection{Remote sensing data}

Satellite-derived data (e.g. $u, v$, sea surface height, and surface chl $a$ ) from altimetry and ocean color data were produced specifically for OUTPACE in the WTSP by Ssalto/Duacs and CLS with support from CNES. The procedures used to generate the data are similar to those described in d'Ovidio et al. (2015), with the result that these products provide higher resolution and quality control measures than is typically available from global products. As described in the following paragraphs, some of these products were produced post-cruise in delayed time, while others were provided during the cruise in near-real time.

Maps of altimetry were generated delayed time by merging along-track observations from the Jason-2, SARAL/AltiKa, CryoSat-2, and HY-2A missions. The regional OUTPACE domain spans 140 to $220^{\circ} \mathrm{E}$, and $30^{\circ} \mathrm{S}$ to the Equator, over the yearlong period of June 2014 to May 2015. The regional product has a resolution of $1 / 8^{\circ}$ using the FES2014 tidal model, and the CNES_CLS_2015 mean sea surface. In order to produce this increase in resolution, among other measures region-specific noise measurements 
and correlation scales were calculated. Beyond the determination of merged absolute dynamic topography and its currents, corrections for cyclogeostrophy and Ekman effects at both the surface and $15 \mathrm{~m}$ depth have been included in separate products. Comparisons between surface velocity program drifters deployed during OUTPACE and numerical Lagrangian particle experiments using these different products indicated that inclusion of an Ekman velocity component at $15 \mathrm{~m}$ produced a more accurate trajectory (Rousselet et al., 2017, this special issue). Therefore, the Ekman inclusive altimetry product was used in the present study.

Both sea surface temperature (SST) and surface chl $a$ composite maps were also generated by CLS/CNES. These products were generated in near-real time during the OUTPACE campaign. Each map, with a $1 / 50^{\circ}$ resolution, uses a 5-day weighted mean of Suomi NPP Viirs measurements. The dataset spans from December 2014 to early May 2015.

\subsection{Dynamic diagnostics and tools}

The determination of the dynamical character of in situ currents surrounding the LDB bloom was implemented with use of the Richardson $(R i)$ number parameter. Classically, the gradient $R i$ number is defined as

$R i=\frac{N^{2}}{\left(\frac{\partial u}{\partial z}\right)^{2}}$,

with $N^{2}$, the stratification, being the square of the BruntVäisälä frequency and $\frac{\partial u}{\partial z}$ being the vertical shear of horizontal velocity. $R i$ is useful in characterizing differing regimes of flow, for example the classical $R i<\frac{1}{4}$ Kelvin-Helmholtz condition for instability. In submesoscale flows, instabilities such as symmetric instability (SI) appear when $R i \leq 1$ (Stone, 1970). The submesoscale regime is commonly accepted to being near $R i \sim 1, R o \sim 1$ (Mahadevan, 2016; McWilliams, 2016). In order to diagnose dynamical regimes from in situ data, we used a formulation from (Thomas et al., 2013) to find the geostrophic component of shear, expressed as

$$
R i_{g}=\frac{f^{2} N^{2}}{\left|\nabla_{\mathrm{h}} b\right|^{2}},
$$

where $b=-\frac{g \rho}{\rho_{0}}$ is the buoyancy (with $g$ the gravitational constant, $\rho$ the density, and $\rho_{0}$ a reference density), $f$ is the Coriolis parameter, and $\nabla_{\mathrm{h}}$ is the horizontal components of the gradient operator. In this paper, we characterized the flow as submesoscale when $R i_{g}$ reached this value of 1 .

The $R i_{g}$ diagnostic was originally designed for instability criteria. Here, we are not searching for instabilities. The fact that $R i_{g}$ solely looks at shear due to buoyancy gradients is useful for considering submesoscale features. In order to more fully investigate the instabilities that are possible in a given dataset, the relative vorticity is required in addition to $R i_{g}$ (see Fig. 1 in Thomas et al., 2013; for example, sufficient cyclonic vorticity can make a water column stable to SI below $R i=1$ ), which is out of the scope of this paper.

The determination of $R i$ required combining the MVP data for the numerator and SADCP data for the denominator and so is limited in resolution by the SADCP bins. Therefore, in calculating $N^{2}, 8 \mathrm{~m}$ bins were produced by averaging the central finite differences from the $1 \mathrm{~m}$ density profile. Since we wished to characterize submesoscale phenomena, the horizontal gradient required for Eq. (2) was left as is, without further re-binning. The calculation of $R i_{g}$ was also calculated at the same $8 \mathrm{~m}$ resolution.

By assuming balanced flow, we can estimate the horizontal scale of density structures in a layer with the first internal Rossby radius of deformation, approximated by (Pedlosky, 2013) as

$R_{\mathrm{D}}=\frac{N H}{\pi f}$,

where $H$ is the depth of the water column (for non-constant stratification, this becomes an integral over depth). As a result, apart from latitude and depth, stratification plays a major role in determining at which horizontal scales one would expect to see balanced motions. Typically, the entire water column is used in this calculation though, for order-ofmagnitude approximations, other depths may be used. For example, a $5000 \mathrm{~m}$ CTD cast near station LDC during OUTPACE (not shown) provided a radius of $65.2 \mathrm{~km}$, consistent with a global climatological atlas for this region (Chelton et al., 1998). The average stratification during LDB produced scales of 160, 570, 2.7, 5.8, and $9.7 \mathrm{~km}$ for the top 20,30,50, 100 , and $200 \mathrm{~m}$, respectively. Using these scales, the horizontal resolution of the MVP transects sufficiently resolved features affecting layers comprising the upper $50 \mathrm{~m}$ and deeper.

The mesoscale structuring of the chl $a$ bloom was evaluated based on altimetry-derived finite size Lyapunov exponents (FSLE), computed following the algorithm of (d'Ovidio et al., 2004). FSLEs were calculated by timeintegrating trajectories on a grid using the velocities described in Sect. 2.3. The trajectories were found with a fourth-order Runge-Kutta method with a $6 \mathrm{~h}$ timestep. Particles were initially separated by $0.05^{\circ}$ (the grid resolution) and reached a final separation of $0.6^{\circ}$. Velocity fields were linearly interpolated in space and time.

All FSLEs were calculated using 30-day backward integrations, meaning that the "final" separation reflects initial displacements that were subsequently brought together (i.e., convergence). FSLE maximal values often form lines, or ridges, that were used to identify possible frontal zones of enhanced strain, along which tracer gradients should generally align. The robustness of FSLE calculations to smallscale errors in velocity fields has been previously studied (Cotté et al., 2011). The 30-day integration timescale we have chosen is likewise robust. Sensitivity analyses (not shown) 
indicate the strongest features are resolved with 10-15-day integrations, with finer detail emerging over 25-30-day integrations. The smallest features are removed by a 0.15 day $^{-1}$ threshold for the analysis in this study. Additionally, in practice FSLEs have been shown to be a useful heuristic in identifying flow manifolds in two-dimensional data. In effect, the FSLEs here represent the emergent structures one would expect to see if the larger-scale mesoscale features visible by satellite were important.

The altimetry-derived currents produced by CLS/CNES were also used to calculate Lagrangian particle trajectories both backward and forward in time, through the use of the Lagrangian diagnostic tool ARIANE (Blanke and Raynaud, 1997; Blanke et al., 1999; Blanke, 1997). Generally, this tool uses either model or empirical output to drive particle trajectories. Since the dominant tracer in this study, chl $a$, is reactive, the initial point for integration of trajectories for ARIANE was somewhat subjective. As a result, we chose here to start when the bloom associated with LDB was at its pinnacle point, namely 6 March 2015, as judged by satellite data. It is reasonable to assume that seeding Lagrangian particles from this maximal point in the surface bloom gave the best chance that the particles would remain in the sphere of bloom water, and would point to both the potential source of the bloom and its endpoint. Lagrangian particles were spaced $1 / 50^{\circ}(\sim 2 \mathrm{~km})$ apart within the chl $a$ contour of $0.3 \mathrm{mg} \mathrm{m}^{-3}$.

\section{Results}

\subsection{Chl $a$ and density distribution and time series}

\subsubsection{MVP observations}

The four MVP transects conducted before and after LDB are shown in Fig. 2. The distributions of chl $a$ fluorescence and isopycnals are presented in panels Fig. 2b-e. During T1 (Fig. 2b), the chl $a$ maxima was initially located near $120 \mathrm{~m}$ depth, where it was then present at $100 \mathrm{~m}$ before being found at the surface near $77 \mathrm{~km}$, inside the patch. Within the patch, a surface signal was present from the surface to $40 \mathrm{~m}$, with a diminished DCM at $80 \mathrm{~m}$. Outside the patch, at $127 \mathrm{~km}$, the DCM was again found near $120 \mathrm{~m}$.

T2 (Fig. 2c) demonstrated a similar pattern, with the DCM found from 120 to $100 \mathrm{~m}$ again, reaching the patch edges at 110 and $222 \mathrm{~km}$. The DCM within the patch was less distinct from the surface signal, while the strongest chl $a$ values were still located within the top $40 \mathrm{~m}$. T3 (Fig. 2d), which followed the same route as T2 but occurred some hours later and in the opposite direction, showed the same structure: a $40 \mathrm{~m}$ surface patch located at 22 and $123 \mathrm{~km}$ that was not distinct from the DCM, with the DCM found again at 100 and then $130 \mathrm{~m}$ by the end of T3, outside the bloom.

The distribution in T4 (Fig. 2e) was sampled a week after T1-T3 and subsequent to station LDB. The bloom was

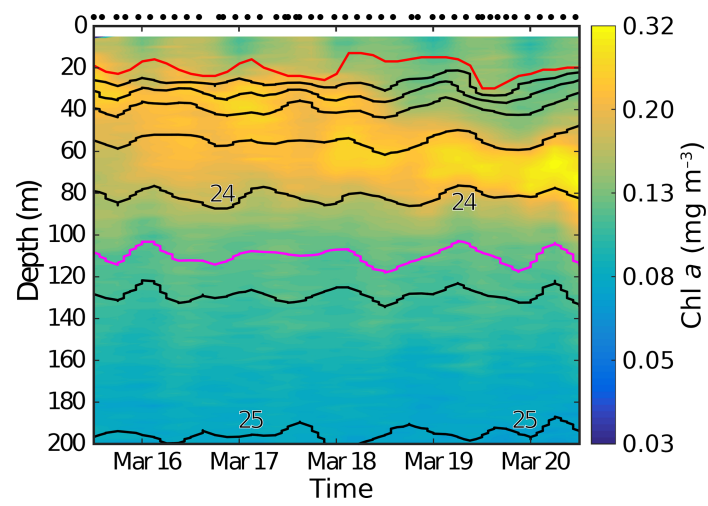

Figure 3. LDB CTD time series (in UTC) of chl $a$. Contours of density anomaly are superimposed in black ranging from 22 to $25 \mathrm{~kg} \mathrm{~m}^{-3}$ in increments of 0.5 . MLD is shown in red, with $D_{\mathrm{NO}_{3}}$ in magenta. Black circles above the panel indicate times of CTD casts.

present from 17 to $110 \mathrm{~km}$ along T4. In this case, a separate DCM at $70 \mathrm{~m}$ was present below the surface signal. Unlike previous transects, the DCM dropped abruptly to $140 \mathrm{~m}$ at $90 \mathrm{~km}$, well before the end of the surface bloom at $110 \mathrm{~km}$.

MLD and density contours throughout these transects were relatively flat, with the MLD centered around $19 \mathrm{~m}$ and the $22,23,24$, and 25 density anomaly contours centered at $16,41,83$, and $182 \mathrm{~m}$, respectively. Among these isopycnals, only the 22 contours reached above the first depth detected by the MVP at $10 \mathrm{~m}$. All of these outcroppings occurred either within the bloom area or adjacent, with the exception of the last at the end of $\mathrm{T} 4$.

\subsubsection{CTD time series}

The chl $a$ structure of LDB, as observed during the 47 CTD casts, is shown in Fig. 3. From the beginning until 18 March, the maximum value of chl $a$ could be found between the 22 and 23 density anomalies, around $30-40 \mathrm{~m}$. After $18 \mathrm{March}$, the chl $a$ max was found at a deeper position near $60 \mathrm{~m}$. Over time, the chl $a$ max deepened and was found between the density anomaly contours of 23.5 and 24 , or $60-80 \mathrm{~m}$ depth. From 18 March onward, the surface concentration of chl $a$ also decreased, whereas the chl $a$ max concentration increased and began to resemble a typical DCM distribution. Oscillations in the surface chl $a$ during the first half of the time series appear, likely due to non-photochemical quenching.

Throughout LDB, the density anomaly contours remained relatively flat. The 22 isopycnals did not outcrop near the surface, unlike that seen in the MVP transects, though the position of LDB within T2 and T3 was inside the region where the 22 isopycnals were found at a similar depth. Upward and downward oscillations of isopycnals indicated the presence of near-inertial oscillations, which was reflected in the SADCP time series that is investigated further in de Verneil 
et al. (2017, this special issue). The MLD, though not formally tied to an isopycnal value, also largely reflected these oscillations. Nitracline depth, which in our formulation was tied to the 24.34 isopycnals, was consistently found between 100 and $120 \mathrm{~m}$ throughout the dataset, well below the chl $a$ max and general bloom area, even when the DCM distribution began to appear towards the end of LDB.

\subsection{Physical and biogeochemical water properties}

Observations of SD12, LDB, and SD13's water structure and biogeochemical properties are presented in Fig. 4. The three stations had similar temperature and salinity profiles, as indicated in the $T-S$ plot of the upper $200 \mathrm{~m}$ (Fig. 4a). All three stations covered a similar density range, with slight variation in their salinities. At the surface, SD12 had slightly lower salinity, while LDB and SD13 overlapped more. At depth, however, SD12 and LDB had closer salinity values, with SD13 showing a salinity maximum at depth.

The nitrate profiles of all three stations (Fig. 4b) showed concentrations near the quantitative threshold limit of the measurement method above $100 \mathrm{~m}$. SD12's nitrate increased the fastest, starting at $100 \mathrm{~m}$, whereas LDB and SD13 matched each other, both increasing at $120 \mathrm{~m}$. The different depths at which nitrate began to increase are similar to the DCM present at both SD12 and SD13 (Fig. 4c), with the DCM near 100 and $120 \mathrm{~m}$, respectively. The chl $a$ profiles for the beginning and end of LDB reflected the changes shown in Fig. 3. Phosphate concentrations (Fig. 4d) for all three stations were nearly equal at $85 \mathrm{~m}$ depth and generally increased with depth. Above $85 \mathrm{~m}$, however, the concentration decreased for SD12 approaching the surface, though it was always above the quantitative measurement threshold. LDB demonstrated a similar decline in phosphate near the surface, but the values were consistently below the detection limit in the top $40 \mathrm{~m}$. By contrast, phosphate values for SD13 were near a steady concentration up to the surface.

\subsection{In situ $R i$ and $R i_{g}$}

The possible presence of balanced, submesoscale currents in the in situ MVP and SADCP datasets was determined by comparing $R i$ and $R i_{g}$. Since both $R i$ and $R i_{g}$ span several orders of magnitude, $\log _{10} R i$ and $\log _{10} R i_{g}$ during $\mathrm{T} 4$ are shown in Fig. 5. All the transects contained similar distributions, and T4 was chosen because of the sharp gradients in chl $a$. The majority of observations of $\log _{10} R i$ and $\log _{10} R i_{g}$ were above 0 , or 1 in normal space, and so here we diagnosed that the circulation was largely not submesoscale in its dynamics. $\log _{10} R i$ (Fig. 5a) values were similar to but slightly lower than $\log _{10} R i_{g}$ (Fig. 5b), demonstrated by a preponderance of saturated shading in Fig. 5b. Larger $\log _{10} R i_{g}$ values were found at depth, with the smallest $\log _{10} R i_{g}$ found near the surface. In the top $50 \mathrm{~m}$, the mean of $\log _{10} R i_{g}$ was 1.38 , whereas it was 1.54 for the entire profile. By contrast, (a)

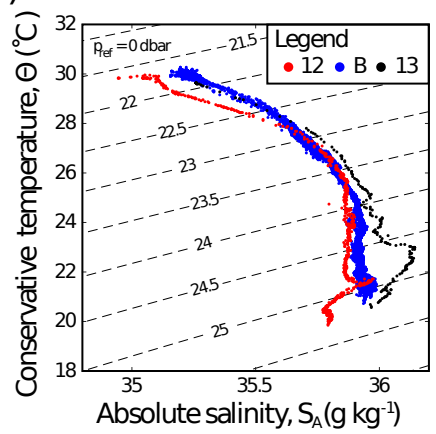

(c)

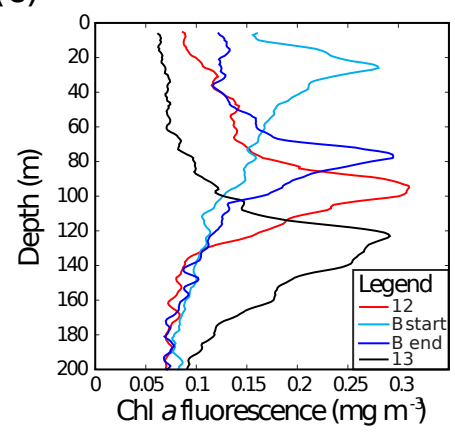

(b)

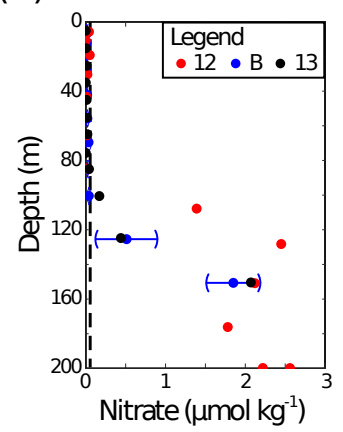

(d)

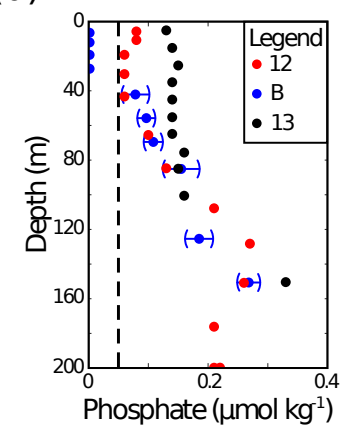

Figure 4. Stations SD12, LDB, and SD13 CTD and bottle data. (a) $\Theta-S_{A}$ diagram, (b) $\mathrm{NO}_{3}$, (c) chl $a$, and (d) $\mathrm{PO}_{4}$ concentrations. SD12 data are shown in red, LDB in blue, and SD13 in black. Quantitative thresholds for $\mathrm{NO}_{3}$ and $\mathrm{PO}_{4}$ are shown by black dashed lines, and any observed values below this threshold are set to 0 . The $95 \%$ confidence intervals are included for the LDB nutrient values.

$\log _{10} R i$ was more consistent between the top $50 \mathrm{~m}$ and all depths, with a mean of 1.35 and 1.36 , respectively. Only $2.2 \%$ of $\log _{10} R i_{g}$ was less than or equal to 0 , with $6 \%$ for $\log _{10} R i$. Additionally, for values less than or equal to 1 , 39 and $35 \%$ of $\log _{10} R i_{g}$ and $\log _{10} R i$, respectively, reached these levels for all depths. $R i$ reached a minimum near the surface for the last $40 \mathrm{~km}$ of T4, which was not reflected in $R i_{g}$. Some structures in $R i$ appeared in a diagonal orientation, such as between 75 and $125 \mathrm{~km}$ at $100 \mathrm{~m}$ depth. Vertical patterns appeared in $R i_{g}$, spanning approximately $10 \mathrm{~km}$ horizontally, where several isopycnals were concurrently found closer to the surface or deeper. One clear example of this occurred near $25 \mathrm{~km}$ within the upper $50 \mathrm{~m}$. Beyond the minimum $R i$ values at the surface near the end of $\mathrm{T} 4$, there were no distinguishing features for either $R i$ or $R i_{g}$ between being inside the chl $a$ bloom and outside, neither at the surface nor at depth.

\subsection{Satellite chl $a$ time series, altimetry-derived FSLE, and ARIANE trajectories}

The remotely sensed distribution of surface chl $a$, calculated FSLEs, and ARIANE Lagrangian particle positions over a period spanning 25 December 2014 to 10 May 2015 is shown 


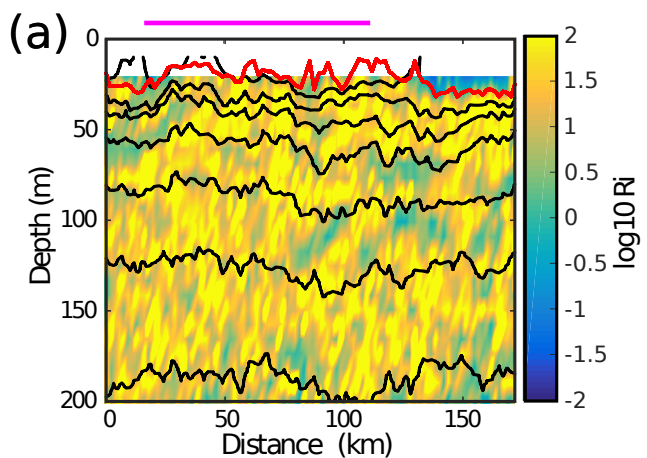

(b)

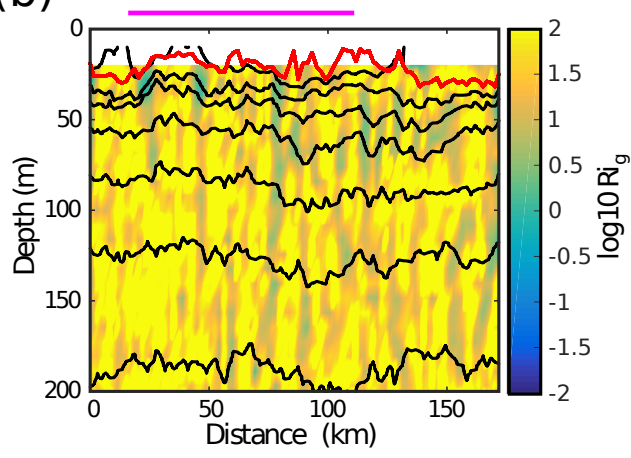

Figure 5. Calculated (a) $R i$ and (b) $R i_{g}$ for MVP T4. Density contours are superimposed in black and MLD in red, with magenta indicating the region inside the bloom, similar to Fig. 2e. Please note the $\log _{10}$ color scale.

in Fig. 6. FSLEs and particles are shaded gray and red, respectively, with $10 \%$ of the particles randomly selected for plotting in all sub-panels. The date 25 December was chosen as the starting point by visually examining the chl $a$ dataset for a pre-bloom period, with a bloom "source" region identified on 13 January centered at $186^{\circ} \mathrm{E}, 20^{\circ} \mathrm{S}$. The temporal evolution of FSLEs and of the Lagrangian particles superimposed on SST is reproduced in Fig. S4 of the Supplement. Additional chl $a$ data, between 10 and 31 January 2015, are also provided in Fig. S6.

The 25 December start date showed a modest chl $a$ region oriented north-south $(\mathrm{N}-\mathrm{S})$ near $186^{\circ} \mathrm{E}$ (Fig. 6a) with several likewise N-S-oriented FSLEs both inside the chl $a$ region and to the east. Lagrangian particles were dispersed over the northern half of the defined region of interest. On 13 January, the identified source region showed the chl $a$ patch localized near an island group located at $20^{\circ} \mathrm{S}, 186^{\circ} \mathrm{E}$ (Fig. 6b). Multiple FSLE ridges were stacked near the chl $a$ patch, indicating the likely flow along these trajectories to the east. Additionally, another ridge appeared, oriented N-S near $189.5^{\circ} \mathrm{E}$, and aligned with a weaker chl $a$ gradient. The Lagrangian particles had now advected west and were flowing south, near the island group "source" region.

On 31 January (Fig. 6c), the FSLEs to the south of the source island group had evolved into a recirculation pattern to the South, creating a lobe of low chl $a$ water near $20.5^{\circ} \mathrm{S}$, $187^{\circ} \mathrm{E}$. The ridge near $189.5^{\circ} \mathrm{E}$ on 13 January had moved westward and collided with the eastward-flowing chl $a$, creating a N-S stretching of the bloom. The northward-flowing arm of the bloom now approached an east-west (E-W) FSLE ridge $\left(17^{\circ} \mathrm{S}, 187^{\circ}\right.$ to $\left.189^{\circ} \mathrm{E}\right)$. At this time, the particles had likewise begun to move from the island group to the east, with some particles overlapping the high chl $a$ bloom.

By 16 February (Fig. 6d), the E-W FSLE ridge was now slanted, as was the chl $a$ patch's northern boundary. To the south, the FSLE ridge that collided with the patch on 31 January had begun to move west, as had the chl $a$ patch spanning $22^{\circ}$ to $20^{\circ} \mathrm{S}, 187^{\circ} \mathrm{E}$. High chl $a$ concentrations positioned at $18.5^{\circ} \mathrm{S}, 189^{\circ} \mathrm{E}$ had advected eastward between the gap in the E-W FSLE ridge and the N-S ridge that collided with the bloom near 31 January. The Lagrangian particles were mostly within the elevated chl $a$ region, and like the bloom water they largely did not cross the FLSE ridge.

On 6 March (Fig. 6e and f), the E-W FSLE ridge had stabilized the formerly northward-flowing bloom waters, and another $\mathrm{N}-\mathrm{S}$ ridge near $191^{\circ} \mathrm{E}$ began to move in from the east. Another FSLE ridge embedded within the southern bloom lobe positioned near $20^{\circ} \mathrm{S}, 187^{\circ} \mathrm{W}$ indicated possible strong flow inside the bloom itself. More $\mathrm{E}-\mathrm{W}$ ridges at $21^{\circ} \mathrm{S}$, $188^{\circ} \mathrm{E}$ also appeared near the bloom's southern boundary. Farther south, apart from the current bloom of study, bands of high and low chl $a$ water appeared amidst E-W FSLE structures. These structures were more or less present from this point on until the end of the study period. Lagrangian particles for 6 March were all located within the high chl $a$ region since this was the chosen particle initialization time.

By 21 March (Fig. 6g), the day of MVP T4 sampling, the $\mathrm{N}-\mathrm{S}$ ridge from earlier had collided with bloom waters and stopped their eastward transit $\left(18^{\circ} \mathrm{S}, 191^{\circ} \mathrm{E}\right)$. The circulation inside the bloom, coinciding with a ridge from $20^{\circ}$ to $18^{\circ} \mathrm{S}$, $188^{\circ} \mathrm{E}$, had entrained low chl $a$ water near the former center of the bloom, producing two lobes of high chl $a$ regions to either side. The particle distribution likewise had these two lobes, and the southern particles had begun to move west, beginning the shearing apart of the chl $a$ bloom.

On 3 April (Fig. 6h) the general decrease in chl $a$ began to show, a trend that continued until 24 April and 10 May (Fig. 6i-j). The N-S FSLE values near T4 on 21 March (now 18 to $19^{\circ} \mathrm{S}, 189^{\circ} \mathrm{E}$ ) had advected westward, along with the recirculation ridge $\left(20^{\circ}\right.$ to $\left.17^{\circ} \mathrm{S}, 187.5^{\circ} \mathrm{E}\right)$ and the remnants of the bloom at LDB. Particles had now spread apart, largely overlapping the decreasing chl $a$ bloom and oriented along FSLE ridgelines. Another E-W ridge $\left(17.5^{\circ} \mathrm{S}, 189-190^{\circ} \mathrm{E}\right)$ asserted itself by 24 April, oriented along a new post-bloom boundary between moderate and low chl $a$ values. 10 May, the end of this study period, now had a region of minimum chl $a$ in the exact region where the bloom was near its peak chl $a$ satellite values on 6 March (compare Fig. $6 f$ and $\mathrm{j}$ ). Numerous $\mathrm{N}-\mathrm{S}$ and $\mathrm{E}-\mathrm{W}$ ridges, generally aligned with the remnant chl $a$ gradients, continued to move west, along with particles generally embedded within them. 


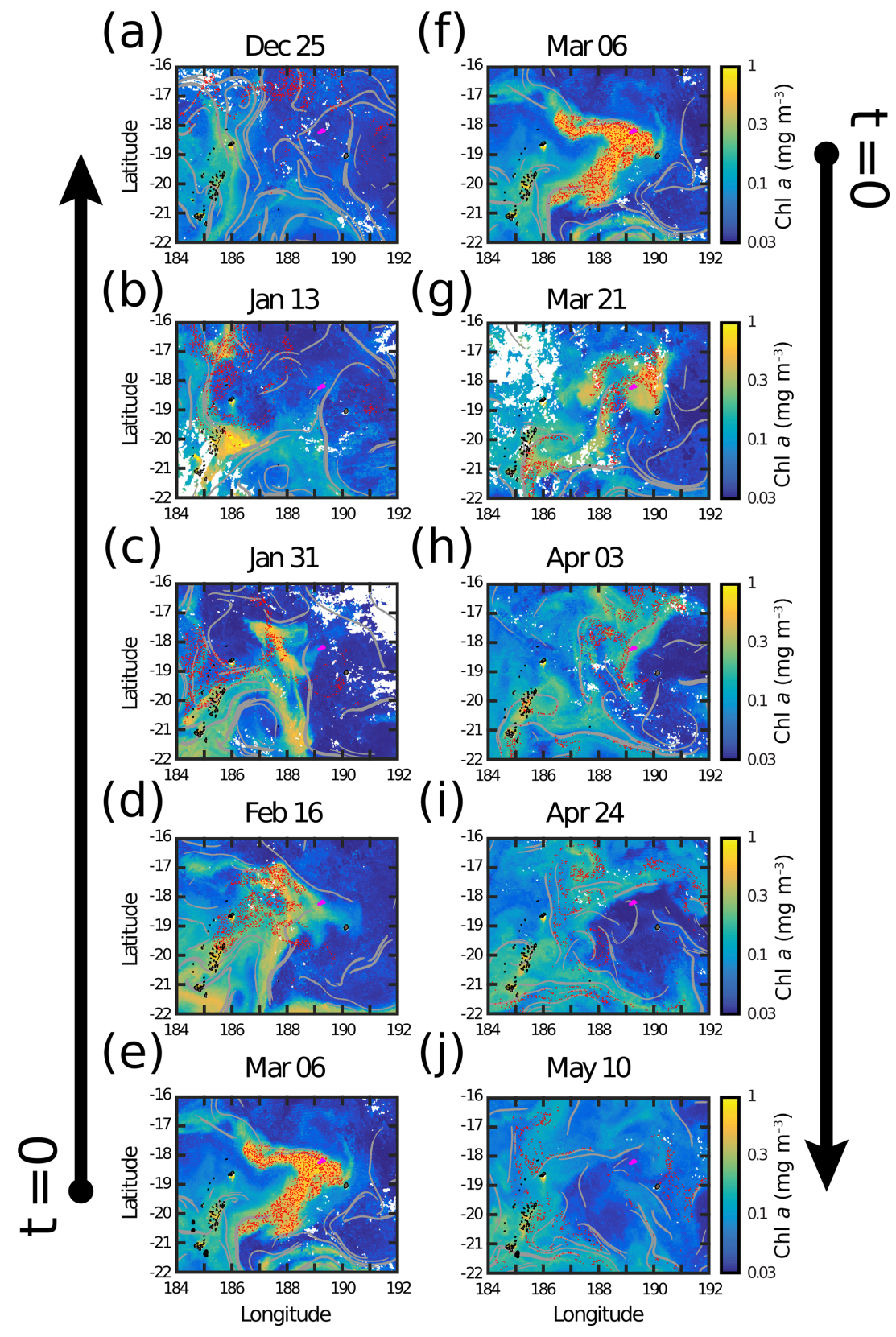

Figure 6. Satellite chl $a$, FSLE, and ARIANE particles for (a) 25 December 2014, (b) 13 January 2015, (c) 31 January, (d) 16 February, (e-f) 6 March (before station LDB sampling), followed by (g) 21 March (the date of MVP T4), concluded by post-bloom (h) 3 April, (i) 24 April, and (j) 10 May. FSLE values above 0.15 day $^{-1}$ are shaded gray. LDB CTD locations are shown in magenta. A randomly selected subsampling of one-tenth of the ARIANE particles was initially chosen to be shown in red.

Statistical properties of the Lagrangian particle positions and their respective chl $a$ values are presented in Fig. 7 . The percentage of Lagrangian particles that stayed within the study region is shown in Fig. 7a. Throughout the entire period of consideration, the percentage of particles within the region was always greater than $70 \%$. During the backward integration, over $95 \%$ of the particles were present until 13 January, the date when the bloom was localized near the island group. Prior to this date, the percentage dropped un- til it was near $70 \%$ on the first day, 25 December 2014. In the forward integration, the proportion of particles steadily dropped, until it was around $80 \%$ in early to mid-April, after which it rose. The downward trend slowly reasserted itself, and by 10 May, the end of the period, the percentage had dropped to near $70 \%$ like in the backward integration.

The mean value of chl $a$ at the particle positions is depicted along with the mean satellite value, as well as the 1 , 25, 75, and $99 \%$ satellite values in Fig. 7b. Moving in either 
(a)

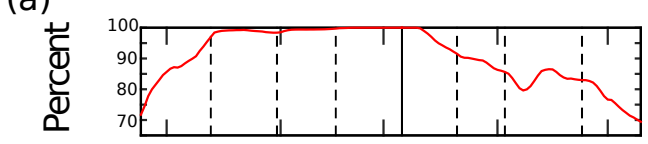

(b)

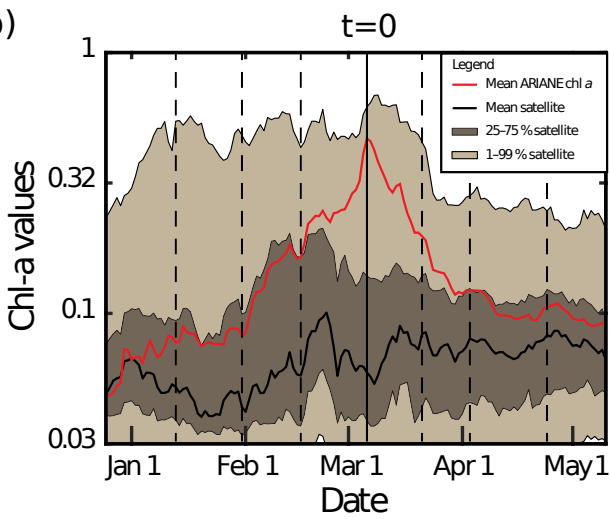

Figure 7. Statistics from ARIANE Lagrangian particle trajectories, from 24 December 2014 to 10 May 2015, with initial date 6 March shown with a solid vertical gray bar and the dates from Fig. 6 in dashed lines. (a) Percentage of particles found inside the bloom region, between $184-192^{\circ} \mathrm{E}$ and $22-16^{\circ} \mathrm{S}$. (b) Mean interpolated chl $a$ value for all Lagrangian particles during backward and forward integrations is in red, with mean chl $a$ from the CLS dataset in black. Dark shading shows region between 25th and 75th percentiles, with light shading for the 1st and 99th.

direction from the 6 March starting point, the mean particle chl $a$ concentration dropped from its initialization peak. The particle mean chl $a$ value was consistently above the mean satellite value, except for a short period at the end of the backward integration in December 2014. Particle mean values reached the $75 \%$ threshold 16 February and 3 April in the backward and forward integrations, respectively. The $99 \%$ satellite value rose from December 2014 to 13 January, when the bloom was identified near the island group. The $99 \%$ value varied around this point until reaching its maximum shortly after 6 March, the initialization date for the particle experiments. After this point, the $99 \%$ satellite value began to decline, with a precipitous drop after 21 March, the date of MVP T4.

\section{Discussion}

\subsection{Chl $a$ bloom processes, physical forcing, and collapse}

The bloom sampled in this study has a number of distinguishing features that differentiate it from the surrounding water sampled during OUTPACE. Together with physical measurements, these characteristics allow for a determination of what combination of biogeochemical processes and physical forcing was responsible for the bloom and its temporal evolution.
Since this study focuses on a surface bloom, there must be some process responsible for the relative accumulation of chl $a$. Ideally, in situ biological rate measurements would have been measured before and during the chl $a$ increase. In addition to the pragmatic difficulty of obtaining all these measurements for all time and space, the satellite data suggest the bloom was already 2 months old by the time of sampling at station LDB, precluding direct observation of its initial conditions. Therefore, one must start with the assumption that the starting conditions for the bloom were similar to surrounding regions (e.g. the chl $a$ distribution pre-bloom on 25 December; Fig. 6a). We can infer, then, that the local increase of chl $a$ in the bloom was linked to a source of new production. For the WTSP, the two main mechanisms to consider are, first, nitrate delivery from below due to advective fluxes and/or diapycnal mixing and, second, $N_{2}$ fixation by diazotrophs.

The data from stations SD12, LDB, and SD13 support the role of $N_{2}$ fixation in creating the bloom and reject nitrate delivery from below. Firstly, the high chl $a$ concentrations in the bloom were located in the top $40 \mathrm{~m}$, as shown by the in situ MVP surveys (Fig. 2) and station LDB CTD time series (Fig. 3). The nitracline, one potential source for new production, was consistently at least $60 \mathrm{~m}$ deeper in the water column in the CTD time series than the bloom. In order to provide an advective flux, the isopycnals present would have at some point needed to traverse the nitracline depth to the bloom at the surface. This did not occur anywhere within the CTD time series. Additionally, the only isopycnal that outcropped during the MVP transects passing inside and outside of the bloom, the $22 \mathrm{~kg} \mathrm{~m}^{-3}$ anomaly, normally resided in the upper $30 \mathrm{~m}$. Therefore, the stable stratification and lack of horizontal density gradients spanning the top $100 \mathrm{~m}$ rule out the potential for a vertical advective flux of nitrate to the surface bloom. These observations do not preclude the possibility that an initial nitrate flux occurred 2 months prior during the bloom's inception, with the water column subsequently mixing and re-stratifying. This possibility is highly unlikely, considering that stations SD12 and SD13 had similar $T-S$ characteristics and nitrate profiles to LDB and yet had a DCM instead of a surface chl $a$ bloom (Fig. 4). These data therefore also remove the possibility of a massive diapycnal mixing event.

Similar surface blooms in oligotrophic regions have been investigated before, with varying mechanisms to explain their initiation. In particular, upwelling, due to mesoscale frontogenesis, and wind forcing are possible causes for surface blooms (Calil et al., 2011; Law et al., 2011). While there are no in situ data during the bloom's appearance in mid-January 2015, sufficient data exist to judge these mechanisms, which would provide advective flux and diapycnal mixing, respectively. Upwelling due to mesoscale frontogenesis can be diagnosed using the omega equation (Hoskins et al., 1978) with the assumptions employed by Calil et al. (2011) for its use with altimetry data. Calculating this forc- 
ing for the OUTPACE bloom resulted in values 3 orders of magnitude smaller than those for the 2008 bloom of Calil et al. (2011) (Fig. S7). As further comparison, climatological data from station ALOHA in that study place phosphate reservoirs for $N_{2}$ fixation at $40 \mathrm{~m}$ depth, shallower than the depths observed during OUTPACE. These results, in addition to the lack of SST gradients one would expect (Fig. S4), make this mechanism unlikely.

Another mechanism is strong wind forcing, such as that provided by tropical cyclones. These storms have been shown to fertilize blooms in oligotrophic waters (Law et al., 2011). Using the value-added altimetry dataset with wind component, the impact of wind was evaluated and found to be relatively small (Fig. S8) and could not create deep mixing. By contrast, another region in the OUTPACE domain witnessed the passage of Cyclone Pam in early March 2015. The satellite imagery before and after its passage corroborate the fertilizing effect of storms in this region (Fig. S9). Whereas the LDB bloom lasted for over 2 months, this increase in chl $a$ lasted approximately a month. Therefore, given the lack of strong forcing, a mechanism must be invoked that can produce blooms of greater magnitude and duration than those produced by passing storms.

The lack of evidence for mixing events or advective nutrient fluxes leads us to consider the parsimonious alternative that the bloom was supported by $N_{2}$ fixation as the source of new production. Diazotrophs, the organisms responsible for $N_{2}$ fixation, are normally concentrated in the surface layer in sufficiently warm water $\left(\geq 25^{\circ} \mathrm{C}\right.$ threshold in Calil et al., 2011). The LDB bloom was found in the upper surface layer, satellite SST was warmer than the $25^{\circ} \mathrm{C}$ threshold for its entirety (Fig. S10), and finally this process was observed directly (Caffin et al., 2017, this special issue). Evidence for $\mathrm{N}_{2}$ fixation's role was also reflected in the nutrient profiles. Nitrate levels in the top $100 \mathrm{~m}$ were consistently below the quantitative threshold, unsurprising since nitrogen is normally the limiting nutrient. Once nitrogen fixation relieves nitrogen limitation at the surface, other inorganic nutrients such as phosphate are consumed. The decreasing concentration of phosphate near the surface at station LDB, as opposed to the constant values at station SD13, supports this interpretation. Interestingly, station SD12 showed a similar decrease, yet not as strongly. This allows for the possibility that stations SD12 and LDB were more alike in the fact that at some point $\mathrm{N}_{2}$ fixation was occurring in situ, though the DCM structure at SD12 and SD13 resembled each other more. The possibility that SD12 also hosted nitrogen fixation, whereas SD13 did not, fits within the overall regional gradient in nitrogen fixation that OUTPACE set out to observe going toward the SPG. For the purpose of this study, it is sufficient to note that the extent of nitrogen fixation present at LDB was likely much larger than at SD12 and in surrounding waters, considering the observed phosphate depletion and the long-lived surface chl $a$ signal associated with the bloom.
Station LDB's CTD time series also showed the decrease of surface chl $a$ and the new formation of a DCM near $80 \mathrm{~m}$. Fluctuations in the surface chl $a$, a possible artifact of nonphotochemical quenching, were small in relation to the large change in chl $a$ that occurs between the first and second halves of the time series. MVP T4 likewise showed the concurrent surface bloom and the appearance of a DCM at $70 \mathrm{~m}$ immediately after station LDB. As previously mentioned when considering nutrient delivery from below, the relatively flat isopycnals also precluded the reverse movement, namely physical subduction of chl $a$ away from the surface. Instead, other mechanisms must be considered. The passive movement of chl $a$ from the surface to a DCM through sinking was possible, but not likely to be a major sink due to the small cell sizes of the plankton concerned (though transparent exopolymer particles may be a factor; Berman-Frank et al., 2017, this special issue). In situ removal of $\operatorname{chl} a$ may have occurred for a number of reasons. First, the exhaustion of phosphate at LDB may have led to a decline in production, which could not match the removal processes of senescence and grazing. Indeed, dissolved inorganic phosphate (DIP) turnover times reached $0.1-0.2$ days above $40 \mathrm{~m}$ depth, a value largely below the critical value of 2 days necessary for Trichodesmium spp., a major $N_{2}$ fixer in this area, to grow (Moutin et al., 2005). Second, the bloom may have fallen victim to increased predation, as abundance of some zooplankton was enhanced (Dolan et al., 2016). Interestingly, even though these biological mechanisms are mediated in situ by planktonic organisms, the regional and simultaneous collapse of the bloom was documented by satellite imagery (Fig. 6g-h), meaning the same mechanisms most likely acted throughout the bloom. The chl $a$ structure at the end of station LDB resembled that of SD12 much more than its initial distribution at the beginning. This observation, in conjunction with evidence of nitrogen fixation near the surface, raises the possibility that at some point station SD12 underwent a similar process and that surface blooms may play a more general role in the region.

\subsection{Surface circulation, chl $a$ advection, and the formation of gradients}

The major focus of this study, apart from diagnosing the bloom's biogeochemical makeup, is to identify which circulation patterns explained the horizontal distribution of the bloom once it was formed, namely submesoscale or mesoscale currents. Comparing the in situ datasets with satellite altimetry currents, the relevant scales of surface motion in the WTSP can be deduced.

As mentioned in the introduction, though the SEC is the mean current advecting water westward from the northern limb of the subtropical gyre, much more kinetic energy is typically found at the mesoscale. Interest has mounted in recent decades in the possibility that submesoscale currents, intensified at the surface, may play a role in affecting nutri- 
ent delivery into the euphotic zone, as well as redistributing biological tracers, including in $N_{2}$ fixation zones (Calil and Richards, 2010). While nutrient delivery has been ruled out for this particular bloom, there remains the possibility that submesoscale motions played a role in the lateral advection of the surface bloom, as well as providing the shear necessary to form the strong chl $a$ gradients observed in the MVP transects. In particular, recent findings highlight both the seasonal (Callies et al., 2015) and geographic (Callies and Ferrari, 2013) occurrence of submesoscale turbulence; for the WTSP, it is unclear whether it should be favored or not. On one hand, it is located away from regions of strong baroclinic currents such as western boundary currents, and according to Eq. (2) the reduced Coriolis parameter relative to temperate latitudes should slightly reduce the geostrophic $R i_{g}$. On the other hand, the late summer stratification may inhibit these motions, making the end result of these competing effects difficult to predict a priori.

The values of $R i$ and $R i_{g}$ present within the top $50 \mathrm{~m}$ of the MVP transects were predominantly greater than 1 , with the majority larger than 10 ( 0 and 1 in $\log$ space, respectively). Considering these two independent measurements of shear agreed in magnitude, and that both occurred outside the dynamical range of consideration, the data thus provided little support for the presence of submesoscale circulation, perfectly balanced or otherwise.

Combining the strong surface stratification, general lack of isopycnal outcroppings (i.e. no strong horizontal density gradients), and absence of correspondence between chl $a$ and density gradients, it should perhaps not be surprising that buoyancy-driven submesoscale circulation was not readily discernable even at the surface in this dataset. If most submesoscale structures are expected to be in the mixed layer, which throughout this dataset was near $20 \mathrm{~m}$, then the subkilometer Rossby radius $R_{D}$ (here found to be $<200 \mathrm{~m}$ ) would not have been resolved by the MVP survey since MVP horizontal resolution is $\sim 2 \mathrm{~km}$. Besides problems of horizontal resolution, the shallow mixed layer also precluded complete vertical resolution by the underway MVP. As a result, though the summertime conditions present during the surveys lend support to reduced submesoscale circulation, the very same conditions make it difficult to state with confidence that the $R i$ and $R i_{g}$ methodology is entirely conclusive. However, since the bloom of interest in these surveys spanned the top $40 \mathrm{~m}$, and covered hundreds of kilometers in horizontal extent, these small features, should they have existed, would not have impacted the full depth range of the bloom, nor would they have significantly affected the horizontal advection of the entire bloom. Furthermore, the strongest gradient in chl $a$ found in MVP T4 had no visible density structure at these scales to suggest a source of horizontal shear to create this gradient.

The possibility remains that during other periods of the year such as winter, with a deeper mixed layer than that observed during the cruise, the horizontal spatial scales of these features would increase and possibly impact the advection of such a bloom. The question thus becomes whether these bloom events occur during winter periods. If not, then the mutually exclusive timing of bloom events and stratification favorable for submesoscale turbulence would preclude its influence on bloom evolution for the region.

The natural horizontal scales of the bloom were more in line with the $R_{D}$ of the entire water column, $\sim 60 \mathrm{~km}$, which is impacted by the mesoscale regime. In our dataset, satellite altimetry-derived currents represented the mesoscale circulation. Whereas the MVP T4 transect revealed no submesoscale source of horizontal shear to create a chl $a$ gradient, the mesoscale circulation did via an FLSE structure present near MVP T4 in Fig. 6g. While FSLEs may not provide the exact regions where chl $a$ gradients form in the station LDB bloom, they help define dynamical boundaries that provide more explanation than the in situ data for why the chl $a$ bloom appeared as it did.

The positions of Lagrangian particles also allow for a better representation of where bloom water advected, as shown in Fig. 7. Firstly, most particles were present in the defined region of interest throughout the time series (Fig. 7a), providing additional support (beyond visual inspection) that the chl $a$ dataset sufficiently covered bloom water relative to the chosen initial time of integration, 6 March. If the chl $a$ satellite time series therefore encompasses most of the bloom water of interest, then the fraction of particles in high chl $a$ water throughout their trajectories, as represented in Fig. 7b, is an indication of the performance of these particles in keeping with the bloom. Evidently, chl $a$ is a reactive tracer and undergoes its own evolution, as shown by the shaded areas in Fig. 7b. By contrast, the temporal evolution of SST, which does not suffer from this deficiency, did not display enough variability in the bloom region to confirm the efficiency of FSLEs or ARIANE particles in representing its advection (Fig. S4 in the Supplement). This is most likely due to the strong regional summertime heating that occurs at these latitudes. Moreover, the particle positions are not reliable over long timescales. Few particles can be found in the bloom on 13 January, when it was localized near a group of islands. Conversely, a second initialization experiment on 13 January failed to produce many particles in the bloom for 6 and 21 March (Supplement, Fig. S5). This limitation may be a result of chl $a$ being reactive or of unresolved motions in the altimetry-derived flow field. Therefore, while the ability of the Lagrangian particles to remain in the region of interest and to accurately represent elevated chl $a$ values (mostly above or near the 75 th percentile) provides positive evidence that mesoscale flows were indeed advecting the bloom water, after around 2 months the accumulated errors due to unresolved flows make direct inspection of particle position uninformative. The FSLEs, in comparison, do not suffer from this sensitivity.

With accurate representation of the advection of bloom water, an interesting picture emerges. Firstly, the location of 
the bloom near an island group on 13 January (Figs. 6b, S5) suggests a possible island effect in the ignition of the bloom. Despite the fact the bloom's beginning was not captured by in situ data, we still suggest a mechanism responsible for causing the bloom. Considering that $\mathrm{N}_{2}$ fixation drove new production, and nearby stations SD12 and SD13 had detectable phosphate levels, alleviation of another necessary and limiting nutrient, iron, was possibly at work. The enrichment of diazotrophs near island inputs, and their subsequent advection (along with their primary production), has been documented previously (Dupouy et al., 2013; Shiozaki et al., 2013). Secondly, the shifting FSLEs and both Lagrangian particle experiments (Figs. 6, S5, and S6) demonstrate the general eastward advection of the bloom from its localized island source in Fig. 6b until its easternmost position in Fig. 6g. This eastward evolution is not what one would expect a priori. Indeed, both the SEC and the mesoscale structures responsible for currents in the altimetry dataset propagate westward, reflected by the migration of $\mathrm{N}-\mathrm{S}$-oriented FSLE ridges the bloom encountered in Fig. $6 \mathrm{~b}-\mathrm{d}$ and $\mathrm{f}-\mathrm{g}$.

Therefore, the complex circulation evoked by a westwardmoving mesoscale field allowed for the counterintuitive eastward advection of water with enhanced biological production at its surface. This was possible due to the bloom occurring in water not associated with the coherent elliptic structures that move west. Instead, the bloom occurred in water outside these structures, with tortuous trajectories hyperbolic in nature (Kirwan et al., 2003; Rypina et al., 2010). Eventually, as the bloom collapses, more particles move west with the mean circulation, as shown in Fig. $6 \mathrm{~h}-\mathrm{j}$. The temporal overlap between the surface bloom's occurrence and maintenance until its collapse, in conjunction with its easternmost transport, is possibly a coincidence. It does suggest, however, the important role that complex mesoscale flows outside of coherent elliptic eddies have in determining where new production eventually ends up.

\section{Conclusions}

In this study, we document a surface chl $a$ bloom observed in the WTSP spanning 2 months from mid-January until mid-March 2015. Large-scale in situ surveys conducted by an MVP platform both confirm the surface signal seen by satellite and further show the lack of the DCM common in the region. A quasi-Lagrangian CTD time series additionally shows the collapse of the surface bloom, also corroborated by satellite. Through the use of chl $a$, density, and nutrient profiles, the delivery of nutrients from depth is ruled out as a mechanism sustaining the bloom. Instead, the surface bloom hosted significant $\mathrm{N}_{2}$ fixation as a source of new production. In the WTSP, the hotspot for $\mathrm{N}_{2}$ fixation in the world, the surface inorganic phosphate from the South Pacific gyre may represent an important nutrient source for maintaining such blooms subsequent to sufficient introduction of iron, possibly due to island effects.

The circulation responsible for advecting the bloom at the surface was satisfactorily represented by altimetry-derived mesoscale currents, with physical structures corresponding to biological gradients. The in situ density and velocity data, in contrast, did not have structures that correspond with the sharp gradients in chl $a$. Additionally, the dynamical nature of the in situ data did not fall within the submesoscale regime. In the ongoing debate between the seasonal and geographic distribution of submesoscale turbulence, this dataset posits the first-order importance of mesoscale circulation in the WTSP summer. The complex trajectories that mesoscale currents create in hyperbolic regions outside of eddies can be of prime importance in advecting blooms, sometimes in counterintuitive directions such as the eastward transport presented here.

Future studies in the region will be necessary to resolve residing questions. For instance, the particular biogeochemical conditions igniting the bloom, here hypothesized to be island-derived iron, cannot be confirmed within this dataset and will require further in situ sampling. Additionally, the presence of submesoscale structures during other parts of the year, such as wintertime with deeper mixed layers, remains unanswered.

However, armed with the information that not only summertime blooms fueled by $\mathrm{N}_{2}$ fixation occur in the WTSP, but that their advection at the surface may be represented by the value-added, high-resolution satellite products such as those produced by CLS/CNES, future studies may begin to quantify the combined interannual impact of $\mathrm{N}_{2}$ fixation and mesoscale transport in distributing new production in this region.

Data availability. All data and metadata are available at the French INSU/CNRS LEFE CYBER database (scientific coordinator: Hervé Claustre; data manager and webmaster: Catherine Schmechtig) at the following web address: http://www.obs-vlfr.fr/proof/php/ outpace/outpace.php (INSU/CNRS LEFE CYBER, 2017).

\section{The Supplement related to this article is available online at https://doi.org/10.5194/bg-14-3471-2017-supplement.}

Competing interests. The authors declare that they have no conflict of interest.

Special issue statement. This article is part of the special issue "Interactions between planktonic organisms and biogeochemical cycles across trophic and $\mathrm{N}_{2}$ fixation gradients in the western tropical South Pacific Ocean: a multidisciplinary approach (OUTPACE)". It is not associated with a conference. 
Acknowledgements. We would like to thank the two anonymous reviewers and Associate Editor who helped in making this a better article. This is a contribution of the OUTPACE (Oligotrophy to UlTra-oligotrophy PACific Experiment) project (Moutin and Bonnet, 2015) funded by the French national research agency (ANR-14-CE01-0007-01), the LEFE-CyBER program (CNRSINSU), the GOPS program (IRD), and CNES (BC T23, ZBC 4500048836). The OUTPACE cruise was managed by MIO (OSU Institut Pytheas, AMU) from Marseilles (France). The authors thank the crew of the RV L'Atalante for outstanding shipboard operations. Gilles Rougier, Marc Picheral, and Lucio Bellomo are warmly thanked for their help in CTD rosette and MVP deployment and data processing. We also thank Audrey Gimenez for $T_{\mathrm{DIP}}$ measurements and Sandra Helias-Nunige for nutrient values. Catherine Schmechtig is thanked for LEFE-CyBER database management. Satellite SST, chl $a$, and altimetry data have been provided by CLS in the framework of CNES funding; we thank Isabelle Pujol and Guillaume Taburet for their support in providing these data. Aurelia Lozingot is acknowledged for administrative aid for the OUTPACE project.

Edited by: Kelvin Richards

Reviewed by: two anonymous referees

\section{References}

Aminot, A. and Kérouel, R.: Dosage automatique des nutriments dans les eaux marines: méthodes en flux continu, Editions Quae, 2007.

Berman-Frank, I., Spungin, D., Belkin, N., Van-Wambeke, F., Gimenez, A., Caffin, M., Stengren, M., Foster, R., Knapp, A., and Bonnet, S.: Programmed cell death in diazotrophs and the fate of $\mathrm{C}$ and $\mathrm{N}$ in the Western Tropical South Pacific, Biogeosciences, in preparation, 2017.

Blanke, B.: ARIANE, available at: http://stockage.univ-brest.fr/ grima/Ariane/ (last access: 12 May 2016), 1997.

Blanke, B. and Raynaud, S.: Kinematics of the Pacific equatorial undercurrent: An Eulerian and Lagrangian approach from GCM results, J. Phys. Oceanogr., 27, 1038-1053, 1997.

Blanke, B., Arhan, M., Madec, G., and Roche, S.: Warm water paths in the equatorial Atlantic as diagnosed with a general circulation model, J. Phys. Oceanogr., 29, 2753-2768, 1999.

Bonnet, S., Caffin, M., Berthelot, H., and Moutin, T.: Hot spot of $\mathrm{N}_{2}$ fixation in the western tropical South Pacific pleads for a spatial decoupling between $N_{2}$ fixation and denitrification, P. Natl. Acad. Sci., 114, E2800-E2801, https://doi.org/10.1073/pnas.1619514114, 2017.

Bouruet-Aubertot, P., Cuyper, Y., Le Goff, H., Rougier, G., de Verneil, A., Doglioli, A., Picheral, M., Yohia, C., Caffin, M., Lefèvre, D., Petrenko, A., and Moutin, T.: Longitudinal contrast in small scale turbulence along $20^{\circ} \mathrm{S}$ in the Pacific Ocean: origin and impact on biogeochemical fluxes, Biogeosciences, in preparation, 2017.

Caffin, M., Moutin, T., Bouruet-Aubertot, P., Doglioli, A., Grosso, O., Helias-Nunige, S., Leblond, N., Gimenez, A., de Verneil, A., and Bonnet, S.: Nitrogen budget in the upper layer of 3 stations "representative" of the Western Tropical South Pacific
Ocean: evidence of high nitrogen fixation rates, Biogeosciences, in preparation, 2017.

Calil, P. and Richards, K.: Transient upwelling hot spots in the oligotrophic North Pacific, J. Geophys. Res.-Oceans, 115, C02003, https://doi.org/10.1029/2009JC005360, 2010.

Calil, P. H., Doney, S. C., Yumimoto, K., Eguchi, K., and Takemura, T.: Episodic upwelling and dust deposition as bloom triggers in low-nutrient, low-chlorophyll regions, J. Geophys. Res.-Oceans, 116, C06030, https://doi.org/10.1029/2010JC006704, 2011.

Callies, J. and Ferrari, R.: Interpreting energy and tracer spectra of upper-ocean turbulence in the submesoscale range $(1-200 \mathrm{~km})$, J. Phys. Oceanogr., 43, 2456-2474, 2013.

Callies, J., Ferrari, R., Klymak, J. M., and Gula, J.: Seasonality in submesoscale turbulence, Nature communications, 6, 2015.

Chaigneau, A. and Pizarro, O.: Mean surface circulation and mesoscale turbulent flow characteristics in the eastern South $\mathrm{Pa}-$ cific from satellite tracked drifters, J. Geophys. Res.-Oceans, 110, C05014, https://doi.org/10.1029/2004JC002628, 2005.

Chelton, D. B., Deszoeke, R. A., Schlax, M. G., El Naggar, K., and Siwertz, N.: Geographical variability of the first baroclinic Rossby radius of deformation, J. Phys. Oceanogr., 28, 433-460, 1998.

Chelton, D. B., Schlax, M. G., Samelson, R. M., and de Szoeke, R. A.: Global observations of large oceanic eddies, Geophys. Res. Lett., 34, L15606, https://doi.org/10.1029/2007GL030812, 2007.

Chen, C.-T. and Millero, F. J.: Speed of sound in seawater at high pressures, The Journal of the Acoustical Society of America, 62, 1129-1135, 1977.

Claustre, H., Sciandra, A., and Vaulot, D.: Introduction to the special section bio-optical and biogeochemical conditions in the South East Pacific in late 2004: the BIOSOPE program, Biogeosciences, 5, 679-691, https://doi.org/10.5194/bg-5-6792008, 2008.

Cotté, C., d'Ovidio, F., Chaigneau, A., Lévy, M., TaupierLetage, I., Mate, B., and Guinet, C.: Scale-dependent interactions of Mediterranean whales with marine dynamics, Limnol. Oceanogr., 56, 219-232, 2011.

de Boyer Montégut, C., Madec, G., Fischer, A. S., Lazar, A., and Iudicone, D.: Mixed layer depth over the global ocean: An examination of profile data and a profilebased climatology, J. Geophys. Res.-Oceans, 109, C12003, https://doi.org/10.1029/2004JC002378, 2004.

de Verneil, A., Rousselet, L., Doglioli, A. M., Petrenko, A. A., Bouruet-Aubertot, P., and Moutin, T.: OUTPACE Long Duration Stations: Physical variability and context of biogeochemical sampling, Biogeosciences, in preparation, 2017.

Doglioli, A. M.: SPASSO, available at: http://www.mio.univ-amu. fr/SPASSO (last access: 24 July 2017), 2013.

Doglioli, A. M., Nencioli, F., Petrenko, A. A., Rougier, G., Fuda, J.-L., and Grima, N.: A software package and hardware tools for in situ experiments in a Lagrangian reference frame, J. Atmos. Ocean. Tech., 30, 1940-1950, 2013.

Dolan, J. R., Gimenez, A., Cornet-Barthaux, V., and de Verneil, A.: Community Structure of Tintinnid Ciliates of the Microzooplankton in the South West Pacific Ocean: Comparison of a High Primary Productivity with a Typical Oligotrophic Site, J. Eukaryotic Microbiol., 63, 813-822, 2016. 
d'Ovidio, F., Fernández, V., Hernández-García, E., and López, C.: Mixing structures in the Mediterranean Sea from finitesize Lyapunov exponents, Geophys. Res. Lett., 31, L17203, https://doi.org/10.1029/2004GL020328, 2004.

d'Ovidio, F., Della Penna, A., Trull, T. W., Nencioli, F., Pujol, M.-I., Rio, M.-H., Park, Y.-H., Cotté, C., Zhou, M., and Blain, S.: The biogeochemical structuring role of horizontal stirring: Lagrangian perspectives on iron delivery downstream of the Kerguelen Plateau, Biogeosciences, 12, 55675581, https://doi.org/10.5194/bg-12-5567-2015, 2015.

Dupouy, C., Benielli-Gary, D., Neveux, J., Dandonneau, Y., and Westberry, T. K.: An algorithm for detecting Trichodesmium surface blooms in the South Western Tropical Pacific, Biogeosciences, 8, 3631-3647, https://doi.org/10.5194/bg-8-36312011, 2011.

Egbert, G. D., Bennett, A. F., and Foreman, M. G.: TOPEX/POSEIDON tides estimated using a global inverse model, 99, 24821-24852, 1994.

Ferrari, R. and Wunsch, C.: Ocean circulation kinetic energy: Reservoirs, sources, and sinks, Annu. Rev. Fluid Mech., 41, 253-282, 2009.

Harris, L. D.: Edge effects and conservation of biotic diversity, Conservation Biology, 2, 330-332, 1988.

Hoskins, B., Draghici, I., and Davies, H.: A new look at the $\omega$ equation, Q. J. Roy. Meteorol. Soc., 104, 31-38, 1978.

INSU/CNRS LEFE CYBER: OUTPACE - Oligotrophy to UITraoligotrophy PACific Experiment, available at: http://www. obs-vlfr.fr/proof/php/outpace/outpace.php, last access: 24 July 2017.

Kirwan, A., Toner, M., and Kantha, L.: Predictability, uncertainty, and hyperbolicity in the ocean, Int. J. Eng. Sci., 41, 249-258, 2003.

Law, C. S., Woodward, E., Ellwood, M., Marriner, A., Bury, S., and Safi, K. A.: Response of surface nutrient inventories and nitrogen fixation to a tropical cyclone in the southwest Pacific, Limnol. Oceanogr., 56, 1372-1385, 2011.

Le Bot, P., Kermabon, C., Lherminier, P., and Gaillard, F.: CASCADE V6. 1: Logiciel de validation et de visualisation des mesures ADCP de coque, OPS/LPO, 2011.

Li, Q. P., Franks, P. J., Ohman, M. D., and Landry, M. R.: Enhanced nitrate fluxes and biological processes at a frontal zone in the southern California current system, J. Plankton Res., 34, 9 https://doi.org/10.1093/plankt/fbs006, 2012.

Longhurst, A. R.: Ecological geography of the sea, Academic Press, 2010.

Mackenzie, K. V.: Nine-term equation for sound speed in the oceans, The Journal of the Acoustical Society of America, 70, 807-812, 1981 .

Mahadevan, A.: The impact of submesoscale physics on primary productivity of plankton, Annu. Rev. Mar. Sci., 8, 161-184, 2016.

Mahadevan, A. and Tandon, A.: An analysis of mechanisms for submesoscale vertical motion at ocean fronts, Ocean Modell., 14, 241-256, 2006

McGillicuddy, D. J., Anderson, L. A., Bates, N. R., Bibby, T., Buesseler, K. O., Carlson, C. A., Davis, C. S., Ewart, C., Falkowski, P. G., Goldthwait, S. A., Hansell, D. A., Jenkins, W. J., Johnson, R., Kosnyrev, V. K., Ledwell, J. R., Li, Q. P., Siegel, D. A., and
Steinberg, D. K.: Eddy/wind interactions stimulate extraordinary mid-ocean plankton blooms, Science, 316, 1021-1026, 2007.

McWilliams, J. C.: Submesoscale currents in the ocean, in: Proc. R. Soc. A, vol. 472, p. 20160117, The Royal Society, 2016.

Moutin, T. and Bonnet, S.: OUTPACE cruise, RV L'Atalante, https://doi.org/10.17600/15000900, 2015.

Moutin, T., Doglioli, A. M., de Verneil, A., and Bonnet, S.: Preface: The Oligotrophy to the UlTra-oligotrophy PACific Experiment (OUTPACE cruise, 18 February to 3 April 2015), Biogeosciences, 14, 3207-3220, https://doi.org/10.5194/bg-143207-2017, 2017.

Moutin, T., Van Den Broeck, N., Beker, B., Dupouy, C., Rimmelin, P., and Le Bouteiller, A.: Phosphate availability controls Trichodesmium spp. biomass in the SW Pacific Ocean, Mar. Ecol. Prog. Ser., 297, 15-21, 2005.

Moutin, T., Karl, D. M., Duhamel, S., Rimmelin, P., Raimbault, P., Van Mooy, B. A. S., and Claustre, H.: Phosphate availability and the ultimate control of new nitrogen input by nitrogen fixation in the tropical Pacific Ocean, Biogeosciences, 5, 95-109, https://doi.org/10.5194/bg-5-95-2008, 2008.

Moutin, T., Van Wambeke, F., and Prieur, L.: Introduction to the Biogeochemistry from the Oligotrophic to the Ultraoligotrophic Mediterranean (BOUM) experiment, Biogeosciences, 9, $3817-$ 3825, https://doi.org/10.5194/bg-9-3817-2012, 2012.

Nagai, T., Gruber, N., Frenzel, H., Lachkar, Z., McWilliams, J. C., and Plattner, G.-K.: Dominant role of eddies and filaments in the offshore transport of carbon and nutrients in the California Current System, J. Geophys. Res.-Oceans, 120, 5318-5341, 2015.

Nencioli, F., Kuwahara, V. S., Dickey, T. D., Rii, Y. M., and Bidigare, R. R.: Physical dynamics and biological implications of a mesoscale eddy in the lee of Hawai'i: Cyclone Opal observations during E-Flux III, Deep Sea Res. Pt. II, 55, 1252-1274, 2008.

Pedlosky, J.: Geophysical fluid dynamics, Springer Science \& Business Media, 2013.

Rousselet, L., de Verneil, A., Doglioli, A., Petrenko, A., Maes, C., and Blanke, B.: Characterization of the mesoscale circulation during the OUTPACE cruise (Western Tropical South Pacific), Biogeosciences, in preparation, 2017.

Rousselet, L., Doglioli, A., Maes, C., Blanke, B., and Petrenko, A.: Impacts of mesoscale activity on the water masses and circulation in the Coral Sea, J. Geophys. Res.-Oceans, 121, 7277-7289, 2016.

Rypina, I. I., Pratt, L. J., Pullen, J., Levin, J., and Gordon, A. L.: Chaotic advection in an archipelago, J. Phys. Oceanogr., 40, 1988-2006, 2010.

Shiozaki, T., Kodama, T., Kitajima, S., Sato, M., and Furuya, K.: Advective transport of diazotrophs and importance of their nitrogen fixation on new and primary production in the western Pacific warm pool, Limnol. Oceanogr, 58, 49-60, 2013.

Sohm, J. A., Webb, E. A., and Capone, D. G.: Emerging patterns of marine nitrogen fixation, Nature Rev. Microbiol., 9, 499-508, 2011.

Stammer, D.: Global characteristics of ocean variability estimated from regional TOPEX/POSEIDON altimeter measurements, J. Phys. Oceanogr., 27, 1743-1769, 1997.

Stone, P. H.: On non-geostrophic baroclinic stability: Part II, J. Atmos. Sci., 27, 721-726, 1970. 
Thomas, L. N., Tandon, A., and Mahadevan, A.: Submesoscale processes and dynamics, Ocean modeling in an Eddying Regime, 17-38, 2008.
Thomas, L. N., Taylor, J. R., Ferrari, R., and Joyce, T. M.: Symmetric instability in the Gulf Stream, Deep Sea Research Part II: Topical Studies in Oceanography, 91, 96-110, 2013. 